\title{
PSA Level Less than Four
}

National Cancer Institute

\section{Source}

National Cancer Institute. PSA Level Less than Four. NCI Thesaurus. Code C153420.

A blood concentration of prostate specific antigen less than $4 \mathrm{ng} / \mathrm{mL}$. 